\title{
EFEITOS DO CONGELAMENTO E DOS CICLOS DE GELO-DEGELO EM MASSAS DE PÃO
}

\author{
LETÍCIA GROFF FUNCK* \\ ALICIA DE FRANCISCO**
}

\begin{abstract}
A presente revisão teve por objetivo esclarecer a interferência do processo de gelo e degelo nos constituintes da massa e nas propriedades finais do pão. Abordou-se a influência do congelamento na rede de glúten, nos grânulos de amido e na ação da levedura. Estudo-se o processo de gelo e degelo da massa, o tempo de descanso e o volume final dos pães. Verificouse que o processo de congelamento da massa de pão modifica os constituintes da massa (levedura, glúten, amido e água), sendo possível a adição de componentes para minimizar essas alterações. É necessário otimizar e padronizar o processo de congelamento da massa para melhorar a qualidade final dos pães.
\end{abstract}

PALAVRAS-CHAVE: MASSA DE PÃO - CONGELAMENTO; MASSA DE PÃO DESCONGELAMENTO; GLÚTEN; LEVEDURA; AMIDO.

\section{INTRODUÇÃO}

Apesar de apresentar teor relativamente baixo de proteínas (8-15\%) e deficiência de alguns aminoácidos essenciais (principalmente lisina), o trigo é a maior fonte de proteínas na dieta humana (POMERANZ, 1988) e a fabricação de pães sua utilização mais importante (HOSENEY e ROGERS, 1990; MACRITCHIE, 1992). A panificação constitui, provavelmente, uma das mais antigas tecnologias conhecidas (GIANNOU, KESSOGLOU e TZIA, 2003).

* Mestranda em Ciência dos Alimentos, Laboratório de Ciência e Tecnologia de Cereais (CERES), Departamento de Ciência e Tecnologia de Alimentos (CAL), Centro de Ciências Agrárias (CCA), Universidade Federal de Santa Catarina (UFSC), Florianópolis (e-mail: letifunck@yahoo.com.br).

** Professora do Programa de Pós-Graduação em Ciência dos Alimentos, CERES/ CAL/CCA/UFSC, Florianópolis (e-mail: alicia@mbox1.ufsc.br). 
Propriedades únicas da fabricação de pães de farinha de trigo podem ser atribuídas à habilidade das proteínas do glúten em formar sistema viscoelástico quando misturado com água (PATIENT e AINSWORTH, 1994). As propriedades viscoelásticas das massas de pães de trigo exercem efeitos profundos nas características de textura e na manutenção da estrutura do produto final (UTHAYAKUMARAN et al., 2000). Assim, medidas da viscoelasticidade da massa (usando técnicas reológicas) conseguem relacionar a composição e a estrutura dos materiais crus (ingredientes básicos e adicionados), aditivos e coadjuvantes de produção com a funcionalidade da massa na padaria (BLOKSMA, 1990a; WALKER e HAZELTON, 1996). Equipamentos ajudam a descrever o comportamento da massa de pão e sua capacidade de reter gás durante os estágios de fermentação, descanso e cozimento pelas medidas de resistência e elasticidade dum pedaço uniformemente formado de massa (WEIPERT, 1992).

Embora as fases sólido-líquida da massa mudem drasticamente durante o processo de panificação, a fase gasosa (bolhas de gás) constitui característica contínua, unicamente desenvolvida durante cada estágio do processo (MARTIN, 2004). O crescimento e a estabilidade de células de gás (bolhas) durante o cozimento da massa são influenciados quanto ao tamanho, distribuição, crescimento e ruptura, tendo maior impacto na qualidade final do pão em termos de textura e volume final (HE e HOSENEY, 1991a).

O mercado de massas de pão congeladas tem crescido constantemente, devido à demanda por produtos assados de conveniência e de alta qualidade (BHATTACHARYA, LANGSTAFF e BERZONSKY, 2003). O processo de congelamento é amplamente usado nas padarias industriais para facilitar a produção de pão e a panificação de varejo, permitindo a compra de pães frescos a qualquer hora (ROUILLÉ et al., 2000). Além disso, facilita o transporte, reduz os custos de produção e as habilidades dos padeiros passam a ser menos essenciais. Por outro lado, o volume e a qualidade dos pães são menores em relação às massas frescas, principalmente com longos tempos de estocagem (RÄSÄNEN, HÄRKÖNEN e AUTIO, 1995).

O objetivo desta revisão foi esclarecer a influência do processo de congelamento e descongelamento nos constituintes da massa e nas 
propriedades finais do pão, a fim de verificar quais os parâmetros a serem considerados na elaboração de massas congeladas.

\section{MASSAS DE PÃO FRESCAS}

A fórmula mínima para a produção de pão inclui farinha, levedura, sal e água (HOSENEY, 1994). Seu processamento pode ser dividido nas operações de formação da massa, fermentação e cozimento. Misturar todos os ingredientes da receita e amassar até o desenvolvimento desejado constitui o procedimento mais simples para sua elaboração.

O pão fresco apresenta curta vida-de-prateleira devido alterações físicas e químicas que ocorrem durante sua estocagem, conhecidas como envelhecimento. Assim, sua qualidade diminui gradualmente ao perder o frescor e a crocância com aumento da firmeza e da rigidez do miolo. O aroma agradável desaparece e o gosto revela sensação de pão amanhecido (GIANNOU, KESSOGLOU e TZIA, 2003).

A quantidade e qualidade do glúten, responsável por formar a estrutura do pão assume grande importância. Geralmente é preferível farinha altamente protéica, obtida de trigo duro, porque produz pães com maior volume e de boa qualidade (GRISWOLD, 1972). Recomenda-se o uso de farinhas de trigo com conteúdo protéico entre 10,5 e 12,0\% para a produção do pão francês convencional (AUTRAN, 1989).

O endosperma do trigo varia em textura (dureza) e aparência (qualidade de vítreo). Geralmente, trigos duros com alto teor protéico tendem a ser vítreos e trigos moles com baixo teor protéico a serem opacos. A dureza é controlada geneticamente (ligações entre proteína e amido no endosperma) e o mecanismo de controle parece ser a quantidade de proteína na amostra. Trigos duros (para pão) têm sido selecionados pela alta absorção de água (HOSENEY, 1994).

A grande absorção de água pela farinha de trigo duro significa elevado rendimento do pão. Essa farinha produz pães em limites mais amplos de períodos de fermentação em relação à farinha de trigo mole, ou de classificação inferior (GRISWOLD, 1972).

Os parâmetros reológicos dinâmicos - G' (módulo de estocagem), G” 
(módulo de perda) e tan $\delta$ (G"/G') - das massas de glúten dependem da cultivar de trigo. Glútens de farinhas com baixa qualidade são menos elásticos e mais viscosos que os de boa qualidade (HE e HOSENEY, 1991b; JANSSEN, VAN VLIET e VEREIJKEN, 1996).

O desenvolvimento da massa pode ser explicado pela formação de sistema contínuo com ligações dissulfeto covalentes de moléculas protéicas distintas, mediante ligações tiol-dissulfeto. A continuidade do sistema depende das ligações não-covalentes, tais como ligações de hidrogênio, ligações hidrofóbicas e ligações entre cadeias (BLOKSMA, 1990b). A ligação entre as proteínas do glúten exerce influência nas propriedades da massa e, conseqüentemente, nos produtos panificáveis. Tradicionalmente, apenas as ligações dissulfeto entre as proteínas são consideradas em massas de pão (KAUFMAN, HOSENEY e FENNEMA, 1986). Entretanto, ligações não-dissulfeto introduzidas pela enzima transglutaminase também podem influenciar as propriedades da massa (GERRARD et al., 2001). O uso de transglutaminase microbiana é recomendado para farinhas com glúten fraco e pobre performance de panificação. A sua adição à farinha reduz a extensibilidade do glúten e aumenta a resistência à extensão (BAUER et al., 2003).

Na produção da massa de pão, os grupos sulfidrilos livres presentes no glúten tendem a se oxidar durante a batedura da massa, transformando-se em pontes dissulfeto. Efeito semelhante pode ser obtido pela adição de agentes oxidantes (bromato de potássio) à farinha, assim como acontece com o envelhecimento da farinha, melhorando as propriedades reológicas do glúten (CHEFTEL, CUQ, LORIENT, 1989; SGARBIERI, 1996).

Melhores massas são obtidas pelo método direto com adição de sal no final da mistura, mantendo-se a temperatura em torno de $17-18^{\circ} \mathrm{C}$ durante o processo de amassamento até o completo desenvolvimento da massa (JACKEL, 1991). A temperatura da massa fresca após a mistura gira em torno de $24-26^{\circ} \mathrm{C}$, sendo reduzida para 19 a $22^{\circ} \mathrm{C}$ na produção de massas congeladas para minimizar a atividade da levedura antes do congelamento (KENNY, GRAU e ARENDT, 2001).

A mistura da massa tem como finalidade a homogeneização dos ingredientes, o desenvolvimento da massa e a oclusão de gás. A 
homogeneização consiste na mistura de todos os ingredientes parar formar a massa (HOSENEY, 1994). No desenvolvimento, a massa retém - $\mathrm{CO}_{2}$ produzido pelas leveduras durante a fermentação. No primeiro estágio de cozimento, a massa se expande pela evaporação de $\mathrm{CO}_{2}$, água e etanol com a elevação da temperatura. Em temperaturas superiores a $60^{\circ} \mathrm{C}$ ocorre a gelatinização do amido, que aumenta marcadamente a viscosidade da massa (BLOKSMA, 1990a). O uso de grânulos de amido gelatinizado, nova tecnologia em crescimento, foi desenvolvida para produzir pães do tipo macio em indústrias de panificação (NAITO et al., 2004).

O tempo de mistura, durante a homogeneização, exerce efeito sobre a massa, sendo que seu aumento provoca elevação na temperatura da massa e afeta a rede de glúten. Temperaturas mais baixas formam massa mais dura e bastão mais curto e o tempo de mistura comprime a rede de glúten (ROUILLÉ, LE BAIL e COURCOUX, 2000).

A qualidade da aparência e a textura final do pão dependem das bolhas formadas na massa, as quais não são criadas durante os processos de descanso e cozimento. Assim, controlando a distribuição do tamanho das bolhas antes da fase de descanso, é possível controlar a textura final do miolo do pão (MARTIN, 2004).

Em pães produzidos com farinha de trigo integral, o farelo e o gérmen são responsáveis (em parte) pelo menor volume do pão. O gérmen contém glutationa, tripeptídeo redutor com grupo sulfidrila $(-\mathrm{SH})$ (GRISWOLD, 1972), que exerce efeito negativo na reologia da massa (WOLT e D’APPOLONIA, 1984a).

\section{MASSAS DE PÃO CONGELADAS}

O maior desafio da indústria de panificação envolve a estocagem da massa por considerável período sem comprometer sua qualidade final (ESSELINK et al., 2003). Durante a década de 80, a produção de alimentos congelados ocupou espaço proeminente nas indústrias alimentícias. Na panificação, essa tendência também tem apresentado notável importância na agregação de valor aos produtos de trigo. Entretanto, as massas congeladas originam produtos mais pobres em qualidade do que massas frescas (BHATTACHARYA, LANGSTAFF 
e BERZONSKY, 2003; NICOLAS et al., 2003). No Brasil, o congelamento de produtos de panificação tem sido pouco estudado (FRANCISCHI, ORMENESE e PIZZINATTO et al., 1998).

Massas congeladas de pão estão sendo vistas como produto que "resolve problemas". Como padeiros especialistas estão se tornando escassos, padarias e restaurantes precisam de produtos que exijam menor conhecimento e instrução para sua produção. Com massas congeladas, as padarias conseguem produzir pães frescos de alta qualidade com custos inferiores (PALMER, 1994). A redução no trabalho e no custo de produção torna-se possível porque o congelamento da massa permite a fabricação descontínua (SEGUCHI et al., 2003) e os pães podem ser preparados durante o horário normal de trabalho.

A qualidade dos produtos congelados de padaria sofre influência da formulação da massa e de parâmetros do processo como, tempo de mistura, velocidade de congelamento, tempo de estocagem e velocidade de degelo. Esses fatores podem agir de forma independente ou sinergicamente para diminuir a atividade da levedura, resultando na redução da produção de $\mathrm{CO}_{2}$ ou dano na rede de glúten, gradual perda da força da massa, declínio na retenção de $\mathrm{CO}_{2}$ e pobre desempenho de panificação (GIANNOU, KESSOGLOU e TZIA, 2003). A estabilidade da massa congelada depende também da qualidade da levedura, dos compostos sulfidrila ( $\mathrm{SH}$ ) liberados, da fermentação antes do congelamento e dos ciclos de gelo-degelo (EL-HADY et al., 1996). Na produção de massas congeladas de pão usa-se método rápido, "semtempo", visando minimizar a fermentação pelas leveduras durante a preparação da massa (INOUE e BUSHUK, 1991).

O congelamento, baseado no princípio físico de separação da água da massa, resulta da formação de cristais de gelo abaixo de $0^{\circ} \mathrm{C}$ (LAAKSONEN e ROOS, 2000). Acredita-se que o dano sobre a massa, associado aos processos de gelo-degelo, seja induzido pela formação de cristais de gelo (VARRIANO-MARSTON, HSU e MAHDI, 1980).

A qualidade geral do pão assado obtido a partir de massas congeladas diminui gradualmente durante a estocagem sob congelamento (INOUE e BUSHUK, 1991; INOUE, SAPIRSTEIN e TAKAYANAGI, 1995; EL- 
HADY et al., 1996; HAVET, MANKAI e LE BAIL, 2000; ESSENLINK et al., 2003) em razão de dois fatores. O decréscimo no poder de aeração da massa (HSU, HOSENEY e SEIB, 1979b) devido ao declínio da viabilidade das leveduras e a perda gradual da força da massa, ou enfraquecimento da estrutura das proteínas do glúten (VARRIANOMARSTON, HSU e MAHDI, 1980; BERGLUND, SHELTON e FREEMAN, 1991; INOUE e BUSHUK, 1991; AUTIO e SINDA, 1992), verificada por microscopia eletrônica e métodos reológicos. Ambos fatores são mais pronunciados com o aumento do tempo de estocagem sob congelamento (EL-HADY, EL-SAMAHY e BRÜMMER, 1999). Ocorre sinergismo entre a velocidade de congelamento na atividade da levedura e na reologia da massa, e portanto no volume final do pão (HAVET, MANKAI e LE BAIL, 2000). Outros fatores podem influenciar as propriedades da massa após o congelamento, como a liberação de componentes com a morte das leveduras (enzimas, agentes químicos como glutationa) (INOUE e BUSHUK, 1991; INOUE et al., 1994).

Pães congelados são produzidos com os mesmos ingredientes que os pães de massa fresca. No entanto, usa-se mais fermento $(4,5 \mathrm{a}$ $6,0 \%$ ) e gordura ( 4,0 a $6,0 \%)$, menos água ( 58,5 a $60,5 \%)$ e a farinha deve conter maior teor de proteínas (12,5 a 13,0\%), ou adição de glúten vital (JACKEL, 1991). O conteúdo de proteínas em farinhas de trigo para produção de massas congeladas para pão francês deve enquadrarse entre 11 e 13\% (NEYRENEUF e VAN DER PLAAT, 1991).

O tempo de mistura interfere na qualidade do pão em relação aos volumes da massa, de $\mathrm{CO}_{2}$ e específico do pão. Maior tempo de mistura (massa completamente desenvolvida) confere os melhores resultados. O uso de ingredientes refrigerados $\left(4^{\circ} \mathrm{C}\right)$ aumenta o tempo de mistura e melhora a qualidade dos pães. Sete dias de estocagem da massa a $-20^{\circ} \mathrm{C}$ não deterioraram a qualidade do sistema de glúten (reduz a elasticidade e aumenta a extensibilidade), mas a levedura torna-se sensível à estocagem (ROUILLÉ, LE BAIL e COURCOUX, 2000).

A altura e o peso específico dos pães sofreram marcada redução após estocagem da massa por 1 dia a $-20^{\circ} \mathrm{C}$ em relação à massa nãocongelada e não-estocada. Entretanto, nenhuma deterioração ocorreu após 3 a 6 dias a $-20^{\circ} \mathrm{C}$ em relação ao primeiro dia (SEGUCHI, NIKAIDOO e MORIMOTO, 2003). 


\subsection{INFLUÊNCIA DO CONGELAMENTO NA REDE DE GLÚTEN}

A perda da força da massa pode ser explicada pela mudança na estrutura do glúten, rede de proteínas capaz de reter $\mathrm{CO}_{2}$ durante a fermentação (NICOLAS et al., 2003). No congelamento, dois processos podem ocorrer simultaneamente e mudar a reologia do glúten (BERGLUND, SHELTON e FREEMAN, 1991). O crescimento de cristais de gelo, que pode romper a rede de glúten mediante danos físicos, e a desidratação do glúten com o crescimento de cristais de gelo (INOUE E BUSHUK, 1991; BOT, 2003).

Os cristais de gelo formados durante a estocagem sob congelamento e os repetidos ciclos de gelo-degelo causam danos físicos na estrutura da proteína do glúten (VARRIANO-MARSTON, HSU e MAHDI, 1980), provocando enfraquecimento das ligações hidrofóbicas, redistribuição da água no sistema de glúten da massa (BERGLUND, SHELTON e FREEMAN, 1991; RÄSÄNEN, HÄRKÖNEN e AUTIO, 1995), perda da retenção de gás (AUTIO e SINDA, 1992; BERGLUND, SHELTON e FREEMAN et al., 1991) e redução no volume final do pão (INOUE e BUSHUK, 1991, 1992). A desuniformidade observada na matriz de glúten poderia reter menos gás, o que contribuiria para estender o período de repouso e reduzir o volume dos pães dessas massas congeladas (BERGLUND, SHELTON e FREEMAN, 1991). Em análise por microscopia eletrônica de varredura (MEV) foi verificada ruptura da massa de pão sem levedura, sugerindo que a recristalização do gelo provocou a ruptura da estrutura da massa (RIBOTTA et al., 2004).

Para a formulação de massa congelada é necessário usar farinha com proteínas de boa qualidade e teor protéico superior ao do pão convencional (NEYRENEUF e VAN DER PLAAT, 1991; INOUE e BUSHUK, 1991, 1992; GÉLINAS, DEAUDELIN e GRENIER, 1995; EL-HADY et al., 1996; FRANCISCHI, ORMENESE e PIZZINATTO, 1998; LU e GRANT, 1999b). A qualidade da proteína (força do glúten) é mais importante que a quantidade (INOUE e BUSHUK, 1992). Podem ser usados agentes oxidantes (ácido ascórbico) que reagem com o glúten para melhorar a capacidade de retenção de gás na massa e produzir pães com maior volume e melhor textura (WANG e PONTES JÚNIOR, 1994). Durante a mistura, esses agentes convertem os grupos SH das proteínas do glúten às ligações SS entre moléculas adjacentes, desenvolvendo a rede de glúten e formando massa mais forte 
(DEMIRALP, CELIK e KÖKSEL, 2000). Assim, o ácido ascórbico reduz a extensibilidade e aumenta a elasticidade da massa (ROUILLÉ, LÊBAIL e COURCOUX et al., 2000).

Foi verificado por MEV que após 24 semanas de estocagem de massa sob congelamento, a matriz de glúten ficou menos contínua, mais rompida, separada dos grânulos de amido e as fibras do glúten mais finas. Isso poderia explicar a pobre retenção de gás e o decréscimo no volume nos pães resultantes (BERGLUND, SHELTON e FREEMAN, 1991). Outro estudo mostrou que após 60 dias de estocagem a $-18^{\circ} \mathrm{C}$ (massas com e sem goma guar e DA TEM - mono- e diacilgliceróis esterificados para ácido mono- e diacetiltartárico), a matriz de glúten foi muito danificada, com fibras mais porosas e finas e menos uniformes. A massa congelada tende à fragmentação, talvez devido à ruptura das fibras de glúten (RIBOTTA et al., 2004). O amido gelatinizado pode compensar essa fragmentação na matriz de glúten danificada (NAITO et al., 2004).

Ocorrem significativas reduções no volume e escore do pão (características externas/aparência, textura, cor da miolo e escore geral) durante a estocagem da massa sob congelamento quando há remoção de ácido ascórbico. A remoção dos condicionadores (lactato esteroil de sódio - SSL, e DATEM) e ácido ascórbico exerce efeito muito maior do que a remoção do oxidante sozinho (NEMETH, PAULLEY e PRESTON, 1996). Os condicionadores melhoram a massa congelada (WOLT e D'APPOLONIA, 1984b; INOUE, SAPIRSTEIN e BUSHUK, 1995), provavelmente por agirem como agentes reforçadores aumentando a estabilidade das massas (WOLT e D'APPOLONIA, 1984b).

Os efeitos adversos encontrados em massas congeladas podem ser reduzidos pelo uso de farinhas fortes (INOUE e BUSHUK, 1992), adicionando glúten (WANG e PONTES JÚNIOR, 1994) ou agentes fortalecedores (SSL ou DATEM de mono- e diglicerídios) (WOLT e D'APPOLONIA, 1984b; INOUE, SAPIRSTEIN e BUSHUK, 1995; NEMETH, PAULLEY e PRESTON, 1996). Apesar da recomendação de trigos com glúten forte para a produção de massas congeladas, cultivares com glúten excessivamente forte podem não alcançar o desempenho desejável (LU e GRANT, 1999a). Farinhas com moderada força de glúten e alta capacidade de gelatinização do amido podem 
ser ideais para manter a integridade da estrutura da massa durante a estocagem sob congelamento e a maciez do miolo do pão após assado (BHATTACHARYA, LANGSTAFF e BERZONSKY, 2003).

Parece que a proteína do glúten responsável pelo controle da expansão do volume do pão é a glutenina, que pode desempenhar papel predominante na melhoria da qualidade dos pães de massa congelada (LU e GRANT, 1999b). As gluteninas podem ser alteradas pelos repetidos ciclos de gelo-degelo e enfraquecer a massa (INOUE et al., 1994).

Maior tempo de estocagem (30 dias a $-18^{\circ} \mathrm{C}$ ) provoca decréscimo na extensibilidade e aumento na resistência máxima (máxima altura da curva obtida no extensógrafo) da massa pela deterioração geral do sistema de glúten (VARRIANO-MARSTON, HSU e MAHDI, 1980; WOLT e D'APPOLONIA, 1984a). Não foram observadas mudanças significativas nas propriedades reológicas durante a estocagem por curto tempo, mas os repetidos ciclos de gelo-degelo produziram significativa redução na resistência e aumento na extensibilidade da massa (INOUE e BUSHUK, 1991). O mesmo foi observado para massas congeladas por 16 semanas, sem ciclos de gelo-degelo (LU e GRANT, 1999a). Assim, as massas elaboradas com farinhas fortes são geralmente resistentes ao dano do congelamento, mas os repetidos ciclos de gelo-degelo enfraquecem sua estrutura (INOUE e BUSHUK, 1991).

Massas congeladas e estocadas durante 1, 7 e 70 dias com 3 ciclos de gelo-degelo durante 7 dias mostraram redução na resistência máxima. A extensibilidade permaneceu relativamente constante nesses períodos, exceto para a estocagem de 70 dias em que apresentou aumento significativo (INOUE et al., 1994). A extensibilidade das massas não mudou significativamente com o aumento do tempo de estocagem de 0 dia a 4 semanas $(36 \mathrm{~mm}$ ). Houve pequena ampliação após 12 semanas ( $37 \mathrm{~mm}$ ) e aumento com dois ciclos de gelo-degelo (40 mm), o que sugere o enfraquecimento da massa (BHATTACHARYA, LANGSTAFF E BERZONSKY, 2003).

O tempo de estocagem sob congelamento (89, 95 e $110 \mathrm{~g}$ para $0,4 \mathrm{e}$ 12 semanas respectivamente) na ausência de ciclos de gelo-degelo aumentou a resistência máxima das massas (BHATTACHARYA, 
LANGSTAFF e BERZONSKY, 2003), provavelmente devido ao seu endurecimento (VARRIANO-MARSTON, HSU e MAHDI, 1980; WOLT e D'APPOLONIA, 1984a). Na presença de dois ciclos de gelo-degelo em 12 semanas, as massas apresentaram significativo declínio na resistência máxima (95 g) possivelmente pela cristalização do gelo (INOUE e BUSHUK, 1992).

Aumento na velocidade de congelamento reduz a elasticidade da massa, provavelmente devido à ruptura de certas ligações do sistema de glúten pela ação mecânica dos cristais de gelo. Velocidade de congelamento mais alta $(3 \mathrm{~m} / \mathrm{s}$ ) produz maior dano (HAVET, MANKAI e LE BAIL, 2000). O congelamento da massa e sua estocagem sob congelamento provocam redução na firmeza e na elasticidade da massa (LU e GRANT, 1999a; RIBOTTA et al., 2004). DATEM e goma guar não conseguem evitar os efeitos do congelamento da massa nos parâmetros reológicos ( $G$ ' e G* - módulo complexo), nem o dano na ultraestrutura (RIBOTTA et al., 2004). O congelamento e a estocagem reduzem $G^{\prime}$ e $G^{*}$, evidenciando redução na firmeza e na elasticidade da massa e indicando o enfraquecimento da rede de glúten, que poderia resultar da liberação de substâncias redutoras a partir das leveduras. Massas não-fermentadas antes do congelamento são mais elásticas do que as fermentadas, que ficam ainda mais viscosas com o aumento do tempo de fermentação (RÄSÄNEN, HÄRKÖNEN e AUTIO, 1995).

O glúten vital supera o efeito desestabilizador do congelamento, aumentando a força de farinha relativamente fraca com adição de 2,0\%. Isto apenas reduz o tempo de fermentação em relação à massa sem adição de glúten, mas não impede a perda de atividade da levedura com o congelamento que provoca redução gradual da produção de gás e aumento no tempo de fermentação (WANG E PONTES JÚNIOR, 1995).

\subsection{INFLUÊNCIA DO CONGELAMENTO NA AÇÃO DA LEVEDURA}

A levedura, responsável pela produção do gás necessário para o desenvolvimento da massa e por características de sabor e aroma do produto final (pães), tem sido amplamente estudada. A formulação da massa, a concentração, a estabilidade, a linhagem, a perda de atividade da levedura e os ciclos gelo-degelo da massa têm se destacado nos estudos. A escolha da linhagem das leveduras e a otimização do 
processo são pontos críticos para a produção de massas congeladas com vida-de-prateleira aceitável (FRANCISCHI, ORMENESE e PIZZINATTO, 1998).

A viabilidade da levedura é afetada pela velocidade de congelamento (NEYRENEUF e DELPUECH, 1993; HAVET, MANKAI e LE BAIL, 2000), tempo de estocagem (HSU, HOSENEY e SEIB, 1979b; BERGLUND e SHELTON, 1993; INOUE et al., 1994) e ciclos de gelodegelo (HSU et al., 1979b; INOUE et al., 1994). Para minimizar esses efeitos utiliza-se maior quantidade de levedura nas massas congeladas, processo "sem-tempo", baixas temperaturas de fabricação e congelamento rápido (NEMETH, PAULLEY e PRESTON, 1996).

O congelamento da levedura contida na massa resulta em redução mais significativa de sua atividade do que o congelamento direto da levedura prensada (HAVET et al., 2000). O congelamento em velocidade mais baixa preserva a atividade da levedura (NEYRENEUF e DELPUECH, 1993), que é sempre maior na superfície do que no centro da massa. As diferenças na atividade da levedura no interior da massa podem ocorrer devido à variação na velocidade de congelamento e à cristalização do gelo (HAVET, MAKAI e LE BAIL, 2000). Contrariamente, observou-se maior produção de $\mathrm{CO}_{2}$ pela levedura com massa congelada em alta velocidade de $\operatorname{ar}(3 \mathrm{~m} / \mathrm{s})$ e congelamento direto a $-20^{\circ} \mathrm{C} \pm 2^{\circ} \mathrm{C}$ após 3 horas. Mas a estocagem sob congelamento por 7 dias aumentou a depressão na produção de gás, indicando redução na atividade da levedura. A aplicação de ciclos de gelo-degelo (1-3) por 4 semanas de estocagem sob congelamento reduziu ainda mais a produção de gás (EL-HADY et al., 1996).

O congelamento provoca a perda da viabilidade das células de levedura, que tem sido atribuída ao congelamento intracelular e ao aumento da concentração interna de solutos. Os efeitos causados incluem baixo $\mathrm{pH}$, desidratação, toxicidade iônica, danos nos processos essenciais de membrana e nos elementos do citoesqueleto e redução da atividade de enzimas glicolíticas (MYERS e ATTFIELD, 1999). É preferível evitar que a levedura seja ativada antes do congelamento, pois os maiores danos à levedura seriam provocados pelos produtos da própria fermentação (WATANABE e BENASSI, 2000). Isso também reduz espaço na estocagem e no transporte das massas congeladas (DE BONA, 2002). 
Recomenda-se rápido manuseio da massa em baixas temperaturas para minimizar a atividade da levedura antes do congelamento. No entanto, os principais problemas que devem ser solucionados envolvem a manutenção da viabilidade (sobrevivência) e a atividade fermentativa (poder de formação de gás) das células durante o congelamento. $O$ congelamento e a estocagem de massas congeladas sem préfermentação não afetam a viabilidade, mas reduzem bastante a produção de gás (MERIC et al., 1995).

O tempo de pré-fermentação afeta a estabilidade da massa nos ciclos de gelo-degelo e menores tempos de fermentação favorecem maiores volumes dos pães. A fermentação completa (40 min) de massas congeladas reduziu o volume da massa em $15 \%$, na média, em relação ao volume dos pães de massa fresca, enquanto a fermentação interrompida ( $25 \mathrm{~min}$ ) reteve ou aumentou o volume de 3 a $13 \%$. O volume dos pães foi mais afetado pelo tempo de fermentação do que pela qualidade da farinha. Mesmo após 2 semanas de estocagem a $-20^{\circ} \mathrm{C}$, pães com fermentação interrompida apresentaram melhor forma que os com fermentação completa e estocados por 1 dia (RÄSÄNEN, HÄRKÖNEN e AUTIO, 1995).

A pré-fermentação prejudica a produção de gás pelas leveduras, pois a maior estabilidade das massas congeladas nesse caso decorre do estado de latência das leveduras. Massas congeladas após fermentação formam pães com qualidade inferior e mais suscetíveis aos danos do congelamento (HSU et al., 1979a).

O enfraquecimento da massa, após ciclos de gelo-degelo, pode ocorrer pelo aumento da concentração de substâncias redutoras lixiviadas das leveduras que provocam a redução das proteínas do glúten, ou da redistribuição da água causada pela mudança na capacidade de absorção de água pela farinha (INOUE e BUSHUK, 1991; INOUE et al., 1994; EL-HADY, EL SAMAHY e BRÜMMER, 1999). As mudanças estruturais observadas em massas submetidas aos ciclos de gelodegelo podem estar associadas ao enfraquecimento da rede de glúten (WOLT e D'APPOLONIA, 1984a) e não à liberação de substâncias redutoras pelas leveduras (AUTIO E SINDA, 1992).

O armazenamento prévio da levedura a $4^{\circ} \mathrm{C}$, durante três semanas, não afeta sua tolerância aos ciclos de gelo-degelo da massa (GÉLINAS, 
LAGIMONIÉRE e RODRIGUES, 1994). Por outro lado, o armazenamento pode proteger as células dos danos causados pelo congelamento e melhorar a tolerância aos ciclos de gelo-degelo quando a massa é fermentada antes de ser congelada (HSU et al., 1979a).

As mudanças na textura da massa do pão em baixas temperaturas geram água livre, o que permite a formação dos cristais de gelo durante a estocagem sob congelamento e possível rompimento dos sistemas de membrana das leveduras, reduzindo sua viabilidade (VARRIANOMARSTON, HSU e MAHDI et al., 1980; BERGLUND, SHELTON e FREEMAN, 1991; TAKANO et al., 2002a). Menor conteúdo de água na massa limita a água livre durante o congelamento, restringindo a formação de cristais de gelo e seus efeitos negativos na qualidade da massa congelada. A cristalização do gelo afeta particularmente as proteínas, diminuindo as propriedades de retenção de gás da massa (GÉLINAS, DEODELINE e GRENIER, 1995). O volume total da massa é maior com menor adição de água, pois reduz a quantidade de água congelável e diminui o efeito dos cristais de gelo no sistema de glúten e nas células de levedura (EL-HADY et al., 1996).

O líquido centrifugado da massa descongelada aumenta com os ciclos de gelo-degelo. A quantidade de água livre nas massas descongeladas aumentou significativamente após 1 dia, levemente após 3 dias, reduzindo-se após 6 dias de estocagem a $-20^{\circ} \mathrm{C}$. Foi observada também forte correlação entre o aumento do líquido centrifugado das massas congeladas e descongeladas e a redução na altura e no volume específico do pão. Há evidências de forte relação entre a quantidade desse líquido com o sal na formulação e produtos da fermentação na massa de pão (SEGUCHI, NIKAIDOO e MORIMOTO, 2003).

Os volumes dos pães submetidos à fermentação em temperaturas inferiores a $32^{\circ} \mathrm{C}$, após o descongelamento da massa, foram superiores aos fermentados a $43^{\circ} \mathrm{C}$, mesmo que o tempo de fermentação seja reduzido com o aumento da temperatura (HOLMES e HOSENEY, 1987).

O volume final e o escore do pão se reduzem rapidamente após 8 semanas de estocagem sob congelamento, quando a massa foi fermentada a $20-22^{\circ} \mathrm{C}$, entre 2 e 3 horas antes do congelamento. Em tempos menores de fermentação (0-1 hora) esses resultados foram 
muito menos evidentes (NEMETH, PAULLEY e PRESTON, 1996). Longos tempos de fermentação afetam a qualidade dos pães de massa congelada pela perda do poder de aeração causada pela redução na viabilidade das leveduras (HSU et al., 1979a; HINO, TAKANO e TANAKA 1987).

A diminuição da qualidade do pão de massa congelada geralmente é atribuída à redução de volume em relação à massa fresca (INOUE e BUSHUK, 1991, 1992; LU E GRANT, 1999a). Isso pode estar relacionado com a morte das leveduras durante o congelamento e conseqüente redução na produção de $\mathrm{CO}_{2}$ e aumento do tempo de repouso da massa (INOUE E BUSHUK, 1992).

Leveduras de interesse tecnológico apresentaram alta resistência aos períodos prolongados de estocagem sob congelamento, associada com atividade fermentativa elevada e baixa sensibilidade aos ciclos de gelo-degelo (FRANCISCHI, HORMENESE e PIZZANATTO, 1998). O uso de leveduras tolerantes ao congelamento alivia os danos nas massas congeladas (TAKANO et al., 2002b). Observou-se que o nível máximo de trealose a ser usado para melhorar a criorresistência da levedura está entre 5-6\% (MERIC et al., 1995). Trealose, edulcorante natural (diglicosídio) encontrado no fermento biológico, é usado como crioprotetor (HIGASHIYAMA, 2002).

A criorresistência da levedura sofre influência do tempo de fermentação antes do congelamento, das velocidades de gelo e degelo, do tempo de estocagem da massa sob congelamento e das flutuações de temperatura. Para superar a esperada perda de atividade durante 0 congelamento utiliza-se maior teor de levedura em relação à massa fresca (GIANNOU, KESSOGLOU e TZIA, 2003). Quantidades de leveduras de $3,75 \%$ e $5,00 \%$ nas massas apresentaram resultados semelhantes e menor extensibilidade em relação a quantidades menores (1,25\% e 2,5\%), sugerindo que no primeiro caso o açúcar fermentável disponível pode ter limitado a produção de gás (INOUE et al., 1994).

Tanto a levedura seca instantânea, quanto a prensada apresentam boa funcionalidade em massas congeladas (GÉLINAS, DEUDELINE e GRENIER, 1995). A primeira produz pães com volumes inferiores aos obtidos com levedura prensada (NEYRENEUF e VAN DER PLAAT, 
1991). Contrariamente, observou-se menor redução na produção de gás com $1,8 \%$ de levedura seca instantânea ativa que com $4 \%$ de levedura prensada na massa após 12 semanas de estocagem sob congelamento (EL-HADY et al., 1996). Leveduras cremosas (líquidas) e prensadas apresentam poder similar de aeração, propriedades de manutenção a $4^{\circ} \mathrm{C}$ e tolerância aos ciclos de gelo-degelo na massa de pão (GÉLINAS, LAGIMONIÉRE e RODRIGUES, 1994).

\subsection{INFLUÊNCIA DO CONGELAMENTO NOS GRÂNULOS DE AMIDO}

Differential Scanning Calorimetry (DSC) constitui ferramenta útil para estudar as transições de primeira ordem, como a gelatinização e a retrogradação do amido durante o cozimento e a estocagem de produtos de padaria (GIASHI, HOSENEY e VARRIANO-MARSTON, 1983; LEÓN, DURÁN e BARBER, 1997). Esses processos podem ser acompanhados pela observação direta das mudanças do amido em massas aquecidas numa assadeira de DSC com temperaturas similares as do centro do miolo, durante o cozimento do pão. O congelamento da massa não afetou significativamente a gelatinização do amido, mas aumentou sua velocidade de retrogradação quando a estocagem foi prolongada para 30 dias (LEÓN, DURÁN e BARBER, 1997).

Utilizando DSC foi verificado que o congelamento e a estocagem da massa a $-18^{\circ} \mathrm{C}$ modificaram as propriedades do amido. Ocorreram leves alterações na sua gelatinização, mas com importante influência na velocidade de retrogradação e na quantidade de amilopectina retrogradada. Em massas congeladas e não-congeladas, assadas em DSC, a extensão da retrogradação da amilopectina aumentou com a redução da temperatura de estocagem. Tal diferença mostrou-se mais evidente em massas congeladas (RIBOTTA, LEÓN e AÑON, 2003). O aumento da entalpia dos amidos após estocagem da massa por 16 semanas sob congelamento, embora pequeno, pode indicar retrogradação nos grânulos de amido durante a estocagem ou descongelamento das massas (LU e GRANT, 1999a).

A entalpia de retrogradação nos géis de amido ( $50 \%$ de umidade) e pães (30-40\% de umidade) depende do conteúdo de água nas amostras durante a estocagem. A magnitude do pico da fusão da 
amilopectina é controlada pela disponibilidade de água durante a retrogradação, enquanto que o conteúdo de água durante a gelatinização exerce pequeno efeito (ZELEZNAK e HOSENEY, 1986). A quantidade de água congelável na massa aumenta com o tempo de estocagem (até a 8ª semana) (LU e GRANT, 1999a). Coincidentemente, ocorre redistribuição da água total presente no sistema durante a estocagem sob congelamento. Além disso, a recristalização dos cristais de gelo durante a estocagem favorece a formação de menor número de cristais com maior tamanho. Ambos processos (migração da água e recristalização do gelo) podem induzir mudanças na estrutura e no arranjo das moléculas de amilose e amilopectina (BERGLUND, SHELTON e FREEMAN, 1991) que se refletem durante a gelatinização e retrogradação do amido (RIBOTTA, LEÓN e AÑON, 2003).

\subsection{PROCESSO DE CONGELAMENTO E DESCONGELAMENTO DA MASSA}

O tipo de congelamento é importante para as massas congeladas, sendo que a velocidade de congelamento afeta mais as propriedades da massa que o tempo de estocagem (EL-HADY et al., 1996). Baixa velocidade previne a morte das leveduras, mas acelera o crescimento de cristais de gelo que podem danificar a rede de glúten (NICOLAS et al., 2003).

Como a velocidade de congelamento afeta a viabilidade da levedura, o congelamento lento é mais adequado do que o rápido. Esse último não permite que a água saia da célula da levedura, resultando na formação de cristais de gelo intracelulares que causam lesões na parede celular e a morte da levedura (HSU, HOSENEY e SEIB, 1979a; PIZZINATO, 1979).

O congelamento pode ser mecânico (transferência do frio feita por corrente de ar em câmara frigorífica a $-40^{\circ} \mathrm{C}$ ) ou pelo sistema criogênico (com $\mathrm{N}_{2}$ líquido e temperaturas inferiores a $-80^{\circ} \mathrm{C}$ ) (FRANCISCHI, ORMENESE e PIZZINATTO, 1998). Esse último processo provoca resfriamento muito rápido e, provavelmente, prejudica a sobrevivência das leveduras, aumentando o tempo de fermentação e reduzindo o volume dos pães após o descongelamento. 
As massas congeladas são menos estáveis em temperatura de estocagem menor que a de congelamento (HSU, HOSENEY e SEIB, 1979a), sendo recomendadas temperaturas de $-18^{\circ} \mathrm{C}$ e $-34^{\circ} \mathrm{C}$, respectivamente. As células de levedura congelam por volta de $-35^{\circ} \mathrm{C}$ e temperaturas inferiores devem ser evitadas, pois resultam em massa congelada com baixa qualidade (HSU, HOSENEY e SEIB, 1979b). Para a produção de pão francês indicam-se as seguintes temperaturas: congelamento a $-34^{\circ} \mathrm{C}$, com taxa de congelamento de $1^{\circ} \mathrm{C}$ e armazenamento a $-20^{\circ} \mathrm{C}$ (NEYRENEUF e V AN DER PLAAT, 1991). Massas produzidas com levedura, congeladas a $-40^{\circ} \mathrm{C}$ e estocadas a $-18^{\circ} \mathrm{C}$ mantém as melhores características do pão durante 20 dias (DE BONA, 2002).

As massas congeladas devem ser descongeladas antes do descanso da massa. Durante o descongelamento, as leveduras desidratadas no congelamento são reidratadas. Recomenda-se o descongelamento a $38^{\circ} \mathrm{C}$ e umidade relativa de $90-95 \%$, pois temperatura elevada danifica menos a levedura que a própria reidratação (HOLMES E HOSENEY, 1987). Para pão francês, o descongelamento deve ocorrer em câmara a $30^{\circ} \mathrm{C}$ e umidade relativa de $85 \%$ (DE BONA, 2002).

Durante a manipulação comercial, as massas podem estar sujeitas a ciclos parciais de gelo-degelo. Assim, quando as massas são descongeladas por 1 hora em temperatura ambiente antes do recongelamento ocorre significativo decréscimo nos volumes finais dos pães. Quanto mais ciclos maior é a perda de volume (HSU, HOSENEY e SEIB, 1979b). Contrariamente, pode não ocorrer diferença significativa no escore do pão durante os tratamentos de gelo-degelo. Estudo mostrou que os volumes dos pães foram levemente maiores com 2 ou 3 ciclos parciais em relação a 0 ou 1 ciclo. Houve significativa redução no escore dos pães, mas não no volume, durante a estocagem sob congelamento sem ciclos gelo-degelo (NEMETH, PAULLEY e PRESTON, 1996). A razão para as diferenças entre esses dois estudos pode residir na formulação da massa, já que no segundo estudo foram utilizados condicionadores de força (SSL e DATEM) e no primeiro não.

Tempos maiores de estocagem da massa sob congelamento provocaram redução no volume dos pães (465 para $385 \mathrm{~mL}$, massa não-congelada e congelada por 4 semanas respectivamente). O mesmo 
ocorreu quando foram aplicados ciclos de gelo-degelo (370 e $320 \mathrm{~mL}$ para 1 ciclo e 3 ciclos durante 4 semanas de congelamento, respectivamente) (EL-HADY et al., 1996).

O teor de água congelável na massa (determinado por DSC em diferentes períodos de tempo e temperatura) aumentou substancialmente após $4(84 \mathrm{~J} / \mathrm{g})$ e $12(86 \mathrm{~J} / \mathrm{g})$ semanas e com dois ciclos parciais de gelo-degelo dentro de 12 semanas $(89 \mathrm{~J} / \mathrm{g}$ ) em relação à massa fresca $(76 \mathrm{~J} / \mathrm{g})$ (BHATTACHARYA, LANGSTAFF e BERZONSKY, 2003). Isto pode ser atribuído ao derretimento e à recristalização do gelo durante os ciclos de gelo-degelo, com subseqüente dano na matriz de glúten e separação das moléculas de água (AUTIO e SINDA, 1992).

O conteúdo de açúcar reduzido foi significativamente menor na massa estocada sob congelamento por 7 dias e com 3 ciclos de gelo-degelo. Tal fato, sugere que ocorre fermentação nas massas durante os períodos de descongelamento e recongelamento, nos quais as temperaturas se elevam para -5 e $-2^{\circ} \mathrm{C}$ durante 12 horas por ciclo (INOUE et al., 1994).

A pré-fermentação interrompida não afeta a estabilidade da estocagem da massa sob congelamento tão drasticamente quanto os ciclos de gelo-degelo (RÄSÄNEN, HÄRKÖNEN e AUTIO, 1995).

\subsection{TEMPO DE DESCANSO E VOLUME DOS PÃES}

Maior tempo de estocagem sob congelamento, geralmente aumenta o tempo de descanso da massa e diminui o volume final do pão (WOLT e D'APPOLONIA, 1984a e b; INOUE e BUSHUK, 1991, 1992; ELHADY et al., 1996; LU e GRANT, 1999a e b). O estudo de RÄSÄNEN, HÄRKÖNEN e AUTIO (1995) mostrou que maior redução no volume dos pães ocorreu durante a primeira semana de estocagem a $-20^{\circ} \mathrm{C} \pm 2^{\circ} \mathrm{C}$ e aumentou após 2 semanas.

A estocagem da massa de pão sob congelamento por 12 semanas aumentou o tempo de descanso, provavelmente por redução adicional na viabilidade das células de levedura. Ocorreu também redução significativa no volume do pão após esse período sem considerar o 
ciclo de gelo-degelo (BHATTACHARYA, LANGSTAFF e BERZONSKY, 2003).

O tempo de descanso aumentou, em média, de 58,2 min após 2 dias de estocagem sob congelamento para 100,2 min após 26 semanas (NEMETH, PAULLEY e PRESTON, 1996), o que pode ser atribuído ao decréscimo na viabilidade das leveduras (WOLT E D'APPOLONIA, 1984b; HINO, TAKANO e TANAKA, 1987).

Elevação da velocidade de congelamento também provoca redução constante no volume específico dos pães (HAVET, MANKAY e LE BAIL, 2000) em razão da produção de gás pelas leveduras (EL-HADY et al., 1996).

As características da qualidade geral visual das massas congeladas são minimamente afetadas pela estocagem prolongada sob congelamento e pelos ciclos de gelo-degelo (NEMETH, PAULLEY e PRESTON, 1996; BHATTACHARYA, LANGSTAFF e BERGONSKY, 2003). Contrariamente, pode-se observar estrutura aberta e textura esmigalhada que reduzem significativamente o escore do pão com a estocagem prolongada (WOLT e D'APPOLONIA, 1984b).

Decréscimo significativo no volume final e no escore do pão ocorrem quando o tempo de mistura antes do congelamento é menor do que o necessário para desenvolver a massa. Esse efeito torna-se mais pronunciado com o aumento do tempo de estocagem sob congelamento (NEMETH, PAULLEY e PRESTON, 1996). A significativa redução no escore do pão pode ser devido ao enfraquecimento da massa associado com a ruptura da matriz protéica de glúten (VARRIANO-MARSTON, HSU e MAHDI, 1980;BERGLUND, SHELTON e FREEMAN, 1991).

Durante o cozimento dos pães, o tipo, o formato, o tamanho, a temperatura e o tempo de cozimento dependem do tipo de forno (convencional ou turbo) e da carga a ser trabalhada (WATANABE e BENASSI, 2000). Para pão francês de $350 \mathrm{~g}$ (tipo "baguete") recomendase $225^{\circ} \mathrm{C}$ durante 25 minutos (NEYRENEUF e V AN DER PLAAT, 1991). Para produtos de massa congelada, o cozimento geralmente não difere muito do convencional, especialmente quando descongelados de forma 
adequada (GIANNOU, KESSOGLOU e TZIA, 2003).

\section{CONSIDERAÇÕES FINAIS}

De acordo com o exposto, quatro constituintes essenciais sofrem modificações com o processo de congelamento das massas de pão: a levedura (fermento), a rede de glúten, os grânulos de amido e a água presentes na massa. A maioria das alterações nesses componentes ocorre devido ao processo de congelamento, estocagem em temperaturas muito baixas (inferiores a $0^{\circ} \mathrm{C}$ ) e ciclos de gelo-degelo. A velocidade de congelamento e o tempo de estocagem também influenciam essas alterações.

Como as leveduras perdem parte de sua viabilidade com o congelamento tem sido utilizadas leveduras criorresistentes e processos de congelamento sem pré-fermentação para evitar tempos maiores de descanso e menores volumes finais do pão. Elevado conteúdo de proteínas nas farinhas também é relevante, visto que a rede de glúten enfraquece com o congelamento e a estocagem, principalmente pela formação de cristais de gelo e liberação de água no sistema da massa de pão.

A fabricação de massas congeladas de pão exige o uso de farinha com elevada força de glúten, leveduras criorresistentes, baixa quantidade de água e temperaturas de congelamento menores do que as de estocagem, evitando-se os ciclos de gelo-degelo e as flutuações de temperatura durante o armazenamento. Além disso, componentes adicionais como glúten vital, hidrocolóides e oxidantes podem melhorar a qualidade dos pães de massa congelada.

Ainda há controvérsias entre os estudos sobre massa de pão congelada, sendo importante estabelecer os métodos de mistura e preparação da massa, os tempos e temperaturas de congelamento e estocagem, 0 número máximo de ciclos de gelo-degelo, o tempo e a temperatura de descongelamento, bem como o tempo e a temperatura de descanso. A otimização e padronização do processo de congelamento das massas evitaria danos nas características gerais e volume final do pão. 


\section{Abstract}

THE EFFECTS OF FROZEN STORAGE AND FREEZE-THAW CYCLES ON WHEAT DOUGHS

This review clarifies the freeze and thaw process interference in the dough ingredients and on the final bread properties. The topics approached were: fresh and frozen dough, influence of freezing on gluten, starch and yeast. Thawing and freezing of the dough, waiting time and final volume of bread were also studied. It was verified that freezing the dough modifies its constituents (yeast, gluten, starch and water) and, therefore, it is possible to add components to reduce these changes. It is necessary to optimize and standardize the process of dough freezing to improve the final bread quality.

KEY-WORDS: DOUGH - FREEZING; DOUGH - THAWING; GLUTEN; YEAST; STARCH.

\section{REFERÊNCIAS}

1 AUTIO, K.; SINDA, E. Frozen doughs: rheological changes and yeast viability. Cereal Chemistry, v.69, p. 409-413, 1992.

2 AUTRAN, J.C. Soft wheat: view from France. Cereal Foods World, v.34, p. 667-676, 1989.

3 BAUER, N.; KOEHLER, P.; WIESER, H.; SCHIEBERLE, P. Studies on effects of microbial transglutaminase on gluten proteins of wheat. II. Rheological properties. Cereal Chemistry, v.80, p. 787-790, 2003.

4 BHATTACHARYA, M.; LANGSTAFF, T.M.; BERZONSKY, W.A. Effect of frozen storage and freeze-thaw cycles on the rheological and baking properties of frozen doughs. Food Research International, v.36, p. 365-372, 2003.

5 BERGLUND, P.T.; SHELTON, D.R. Effect of frozen storage duration on firming properties of breads baked from frozen doughs. Cereal Foods World, v.38, p. 89-93, 1993.

6 BERGLUND, P.T.; SHELTON, D.R.; FREEMAN, T. Frozen bread dough ultrastructure as affected by duration of frozen storage and freezethaw cycles. Cereal Chemistry, v.68, p. 105-107, 1991.

7 BLOKSMA, A.H. Rheology of the breadmaking process. Cereal Foods World, v.35, p. 228-236, 1990a.

8 BLOKSMA, A.H. Dough structure, dough rheology, and baking quality. 
Cereal Foods World, v.35, p.237-244, 1990b.

9 BOT, A. Differencial scanning calorimetric study on the effects of frozen storage on gluten and dough. Cereal Chemistry, v.80, p. 366-370, 2003.

10 CHEFTEL, J.C.; CUQ, J.L.; LORIENT, D. Proteínas alimentares. Zaragoza: Acribia, 1989. p. 235-253.

11 DE BONA, S. Estudos da viabilidade da produção de pão francês a partir de massa congelada. Florianópolis, 2002. 130 f. Dissertação (Mestrado em Engenharia de Alimentos), Departamento de Engenharia de Alimentos, Universidade Federal de Santa Catarina.

12 DEMIRALP, H.; CELIK, S.; KÖKSEL, H. Effects of oxidizing agents and defatting on the electrophoretic patterns of flour proteins during dough mixing. European Food Research and Technology, v.211, p. 322-325, 2000.

13 EL-HADY, E.A.; EL-SAMAHY, S.K.; SEIBEL, W.; BRÜMMER, J. M. Changes in gas production and retention in non-prefermented frozen wheat doughs. Cereal Chemistry, v.73, p. 472-477, 1996.

14 EL-HADY, E.A.; EL-SAMAHY, S.K.; BRÜMMER, J. M. Effect of oxidants, sodium-stearoyl-2-lactylate and their mixtures on rheological and baking properties of nonprefermented frozen doughs. LebensmittelWissenschaft und-Technologie, v.32, p. 446-454, 1999.

15 ESSELINK, E.F.J.; VANAALST, H.; MALIEPAARD, M.; VAN DUYNHOVEN, J.P.M. Long-term storage effect in frozen dough by spectroscopy and microscopy. Cereal Chemistry, v.80, p. 396-403, 2003.

16 FRANCISCHI, M.L.P.; ORMENESE, R.C.S.C.; PIZZINATTO, A. Tecnologia de produção de pães a partir de massas congeladas. Boletim da SBCTA, v.32, p. 209-214, 1998.

17 GÉLINAS, P.; DEAUDELIN, I.; GRENIER, M. Frozen dough: effects of dough shape, water content, and sheeting-molding conditions. Cereal Foods World, v.40, p. 124-126, 1995.

18 GÉLINAS, P.; LAGIMONIÈRE, M.; RODRIGUES, N. Performance of cream or compressed yeast in frozen and nonfrozen doughs. Cereal Chemistry, v.71, p. 183-186, 1994.

19 GERRARD, J.A.; FAYLE, S.E.; BROWN, P.A.; SUTTON, K.H.; SIMMONS, 
L.; RASIAH, I. Effects of microbial transglutaminase on the wheat proteins of bread and croissant dough. Journal of Food Science, v.66, p. 782-786, 2001.

20 GIANNOU, V.; KESSOGLOU, V.; TZIA, C. Quality and safety characteristics of bread made from frozen dough. Trends in Food Science \& Technology, v.14, p. 99-108 2003.

21 GIASHI, K.; HOSENEY, R.; VARRIANO-MARSTON, E. Effects of flour components and dough ingredients on starch gelatinization. Cereal Chemistry, v.60, p.58-61, 1983.

22 GRISWOLD, R.M. Estudo experimental dos alimentos. São Paulo: Edgar Blücher, 1972. p. 292-293.

23 HAVET, M.; MANKAI, M.; LE BAIL, A. Influence of the freezing condition on the baking performances of French frozen dough. Journal of Food Engineering, v.45, p. 139-145, 2000.

24 HE, H.; HOSENEY, R.C. Gas retention of different cereal flours. Cereal Chemistry, v.68, p. 334-336, 1991a.

25 HE, H.; HOSENEY, R.C. Differences in gas retention, protein solubility and rheological properties between flours of different baking quality. Cereal Chemistry, v.68, p. 526-530, 1991b.

26 HIGASHIYAMA, T. Novel functions and applications of trehalose. Pure Applied Chemistry, v.74, p. 1263-1269, 2002.

27 HINO, A.; TAKANO, H.; TANAKA, Y. New freeze-tolerant yeast for frozen dough preparations. Cereal Chemistry, v.64, p.269-275, 1987.

28 HOLMES, J.T.; HOSENEY, R.C. Frozen doughs: freezing and thawing rates and the potential using a combination of yeast and chemical leavening. Cereal Chemistry, v.64, p.348-351, 1987.

29 HOSENEY, R.C. Principles of cereal science and technology. St. Paul: American Association of Cereal Chemists, 1994. p. 1-13.

30 HOSENEY, R.C.; ROGERS, D.E. The formation and properties of wheat flour doughs. Critical Reviews in Food Science and Nutrition, v.29, p.73-93, 1990.

31 HSU, K.H.; HOSENEY, R.C.; SEIB, P.A. Frozen dough. I. Factors affecting stability of yeasted doughs. Cereal Chemistry, v.56, p. 419-423, 1979a. 
32 HSU, K.H.; HOSENEY, R.C.; SEIB, P.A. Frozen dough. II. Effect of freezing and storing conditions on the stability of yeasted doughs. Cereal Chemistry, v.56, p. 424-426, 1979 b.

33 INOUE, Y.; BUSHUK, W. Studies on frozen dough. I. Effects of frozen storage and freeze-thaw cycles on baking and rheological properties. Cereal Chemistry, v.68, p. 627-631, 1991.

34 INOUE, Y.; BUSHUK, W. Studies on frozen dough. II. Flour quality requirements for bread production from frozen dough. Cereal Chemistry, v.69, p. 423-428, 1992.

35 INOUE, Y.; SAPIRSTEIN, H.D.; TAKAYANAGI, S.; BUSHUK, W. Studies on frozen dough. III. Some factors involved in dough weakening during frozen storage and thaw-freeze cycles. Cereal Chemistry, v.71, p. 118$121,1994$.

36 INOUE, Y.; SAPIRSTEIN, H.D.; BUSHUK, W. Studies on frozen doughs. IV. Effect of shortening systems on baking and rheological properties. Cereal Chemistry, v.72, p. 221-224, 1995.

37 JACKEL, S.S. Frozen dough opportunities keep heating up. Cereal Foods World, v.36, p. 529, 1991.

38 JANSSEN, A.M.; VAN VLIET, T.; VEREIJKEN, J.M. Rheological behaviour of wheat glutens at small and large deformations. Comparison of two glutens differing in bread making potential. Journal of Cereal Science, v. 23, p. 19-31, 1996.

39 KAUFMAN, S.P.; HOSENEY, R.C.; FENNEMA, O. Dough rheology - a review of structural models and the role of disulfide interchange reactions. Cereal Foods World, v.31, p. 820-824, 1986.

40 KENNY, S.; GRAU, H.; ARENDT, E.K. Use of response surface methodology to investigate the effects of processing conditions on frozen dough quality and stability. European Food Research and Technology, v.213, p. 323-328, 2001.

41 LAAKSONEN, T.; ROOS, Y.H. Thermal, dynamic-mechanical, and dielectric analysis of phase and state transitions of frozen wheat doughs. Journal of Cereal Science, v.32, p. 281-292, 2000.

42 LÉON, A.; DURÁN, E.; BARBER, C. A new approach to study starch changes occurring in dough baking process and during bread storage. Zeitschrift für Lebensmittel Unstersuchung Forschung, v.204, p. 316- 
320, 1997.

43 LU, W.; GRANT, L. Effects of prolonged storage at freezing temperatures on starch and baking quality of frozen doughs. Cereal Chemistry, v.76, p. $656-662,1999 a$.

44 LU, W.; GRANT, L. Role of flour fractions in breadmaking quality of frozen dough. Cereal Chemistry, v.76, p. 663-667, 1999b.

45 MACRITCHIE, F. Physico-chemical properties of wheat proteins in relation to functionality. Advances in Food and Nutrition Research, v.36, p. 1-87, 1992.

46 MARTIN, P. Controlling the breadmaking process: the role of bubbles in bread. Cereal Foods World, v.49, p. 72-75, 2004.

47 MERIC, L.; LAMBERT-GUILOIS, S.; NEYRENEUF, O.; RICHARDMOLARD, D. Cryoresistance of baker's yeast Saccharomyces cerevisiae in frozen dough: contribution of cellular trehalose. Cereal Chemistry, v.72, p. 609-615, 1995.

48 MYERS, D.K.; ATTFIELD, P.V. Intracellular concentration of exogenous glycerol in Saccharomyces cerevisiae provides for improved leavening of frozen sweet doughs. Food Microbiology, v.16, p. 45-51, 1999.

49 NAITO, S.; FUKAMI, S.; MIZOKAMI, Y.; ISHIDA, N.; TAKANO, H.; KOIZUMI, M.; KANO, $\mathrm{H}$. Effect of freeze-thaw cycles on the gluten fibrils and crumb grain structure of breads made from frozen doughs. Cereal Chemistry, v.81, p. 80-86, 2004.

50 NEMETH, L.J.; PAULLEY, F.G.; PRESTON, K.R. Effects of ingredients and processing conditions on the frozen dough bread quality of Canada Western Red Spring wheat flour during prolonged storage. Food Research International, v.29, p. 609-616, 1996.

51 NEYRENEUF, O.; DELPUECH, B. Freezing experiments on yeasted dough slabs. Effects of cryogenic temperatures on the baking performance. Cereal Chemistry, v.70, p. 109-111, 1993.

52 NEYRENEUF, O.; VAN DER PLAAT, J.B. Preparation of frozen french bread dough with improved stability. Cereal Chemistry, v.68, p. 60-66, 1991.

53 NICOLAS, Y.; SMIT, R.J.M.; VAN AALST, H.; ESSELINK, F.J.; WEEGELS, P.L.; AGTEROF, W.G.M. Effect of storage time and temperature on 
rheological and microstructural properties of gluten. Cereal Chemistry, v.80, p. 371-377, 2003.

54 PALMER, E. Food companies are buying into frozen dough. Milling \& Baking News, v.73, p. 28-30, 1994.

55 PATIENT, D.;AINSWORTH, P. The chemistry of flour and bread. Nutrition \& Food Science, v.94, p. 22-24, 1994.

56 PIZZINATTO, A. Fatores que afetam a estabilidade e o desempenho de massas congeladas de pão. Boletim do ITAL, v.16, p. 215-226, 1979.

57 POMERANZ, Y. Wheat is unique. St. Paul: American Association of Cereal Chemists, 1988.

58 RÄSÄNEN, J.; HÄRKÖNEN, H.; AUTIO, K. Freeze-thaw stability of prefermented frozen lean wheat doughs: effect of flour quality and fermentation time. Cereal Chemistry, v.72, p. 637-642, 1995.

59 RIBOTTA, P.D.; LEÓN, A.E.; AÑÓN, M.C. Effect of freezing and frozen storage on the gelatinization and retrogradation of amylopectin in dough baked in a differential scanning calorimeter. Food Research International, v.36, p. 357-363, 2003.

60 RIBOTTA, P.D.; PÉREZ, G.T.; LEÓN, A.E.; AÑÓN, M.C. Effect of emulsifier and guar gum on micro-structural, rheological and baking performance of frozen bread dough. Food Hydrocolloids, v.18, p. 305-313, 2004.

61 ROUILLÉ, J.; LE BAIL, A.; COURCOUX, P. Influence of formulation and mixing conditions on breadmaking qualities of french frozen dough. Journal of Food Engineering, v.43, p. 197-203, 2000.

62 SEGUCHI, M.; NIKAIDOO, S.; MORIMOTO, N. Centrifuged liquid and breadmaking properties of frozen-and-thawed bread dough. Cereal Chemistry, v.80, p. 264-268, 2003.

63 SGARBIERI, V.C. Proteínas em alimentos protéicos. São Paulo: Livraria Varela, 1996. p. 184-193.

64 TAKANO, H.; ISHIDA, N.; KOIZUMI, M.; KANO H. Imaging of the fermentation process of bread dough and the grain structure of baked breads by magnetic resonance imaging. Journal of Food Science, v.67, p.244-250, 2002a. 
65 TAKANO, H.; NAITO, S.; ISHIDA, N.; KOIZUMI, M.; KANO H. Fermentation process and grain structure of baked breads from frozen dough using freeze-tolerant yeast. Journal of Food Science, v.67, p. 2725-2733, $2002 b$.

66 UTHAYAKUMARAN, S.; NEWBERRY, M.; KEENTOK, M.; STODDARD, F.L.; BEKES, F. Basic rheology of bread dough with modified protein content and glutenin-to-gliadin ratios. Cereal Chemistry, v.77, p. 744$749,2000$.

67 VARRIANO-MARSTON, E.; HSU, K.H.; MAHDI, J. Rheological and structural changes in frozen doughs. Baker's Digest, v.54, p. 32-41, 1980

68 WALKER, C.E.; HAZELTON, J.L. Dough rheological tests. Cereal Foods World, v.41, p. 23-28, 1996.

69 WANG, Z.J.; PONTES JÚNIOR, J.G. Improving frozen dough qualities with the addition of vital wheat gluten. Cereal Foods World, v.39, p. 500-503, 1994.

70 WATANABE, E.; BENASSI, V.T. O uso de massa congelada na produção de pão. Boletim do CEPPA, v.18, p. 71-84, 2000.

71 WEIPERT, D. Descriptive and fundamental rheometry in a new light. Cereal Foods World, v.37, p. 15-24, 1992.

72 WOLT, M.J.; D'APPOLONIA, B.L. Factors involved in the stability of frozen dough. I. The influence of yeast reducing compounds on frozen-dough stability. Cereal Chemistry, v.61, p. 209-212, 1984a.

73 WOLT, M.J.; D'APPOLONIA, B.L. Factors involved in the stability of frozen dough. II. The effects of yeast type, flour type, and dough additives on frozen-dough stability. Cereal Chemistry, v.61, p.213-221, 1984b.

74 ZELEZNAK, K.; HOSENEY, R. The role of water in the retrogradation of wheat starch gels and bread crumb. Cereal Chemistry, v.63, p. 407411, 1986.

\section{AGRADECIMENTOS}

CAPES - Coordenação de Aperfeiçoamento de Pessoal de Nível Superior. 